\title{
Obstructive Jaundice, Study of 33 Cases in Department of Visceral Surgery, Donka National Hospital
}

\author{
Abdoulaye Korse Balde ${ }^{1}$, Oumar Taibata Balde ${ }^{1}$, Ahmed Boubacar Barry ${ }^{1}$, Soriba Naby Camara ${ }^{2}$, \\ Hamidou Sylla ${ }^{1}$, Aissatou Taran Diallo ${ }^{3}$, Amadou Dioulde Diallo ${ }^{1}$, Fode Lansana Camara ${ }^{1}$, \\ Alpha Madiou Barry ${ }^{1}$, Sneha Ballah ${ }^{4}$ \\ ${ }^{1}$ Department of Visceral Surgery, University Gamal Abdel Nasser of Conakry, Conakry, Guinea \\ ${ }^{2}$ Department of Visceral Surgery, Friendship Hospital of Kipe, University Gamal Abdel Nasser of Conakry, Conakry Guinea \\ ${ }^{3}$ Department of General Surgery, University Gamal Abdel Nasser of Conakry Conakry, Guinea \\ ${ }^{4}$ Department of General Surgery, Sir Seewoosagur Ramgoolam North Hospital, University of Mauritius, Mauritius
}

Email address:

csoribanaby@yahoo.com (S. Ballah), baldakor@gmail.com (A. K. Balde), taibataoumar@yahoo.com (O. T. Balde)

\section{To cite this article:}

Abdoulaye Korse Balde, Oumar Taibata Balde, Ahmed Boubacar Barry, Soriba Naby Camara, Hamidou Sylla, Aissatou Taran Diallo, Amadou Dioulde Diallo, Fode Lansana Camara, Alpha Madiou Barry, Sneha Ballah. Obstructive Jaundice, Study of 33 Cases in Department of Visceral Surgery, Donka National Hospital. Journal of Cancer Treatment and Research. Vol. 4, No. 2, 2016, pp. 16-20.

doi: $10.11648 /$ j.jetr.20160402.11

Received: June 12, 2016; Accepted: June 20, 2016; Published: July 23, 2016

\begin{abstract}
Icterus or jaundice is a yellow staining of the skin and mucous membranes which occurs secondary to elevated bilirubin levels in the blood. Obstructive jaundice corresponds to a mechanical obstacle in the biliary pathways. The definitive diagnosis of obstructive jaundice in preoperative patients remains a challenge. The aim of this study was to present a number of epidemiological aspects to highlight the problems faced with diagnosis and treatment in order to ameliorate the management and prognosis of patients with obstructive jaundice. It was a retrospective study conducted on 17 male patients and 16 female patients with an average age of 51-54 years, who were surgically treated for obstructive jaundice. The main clinical presentation was characterized by icterus, pruritus and abdominal pain. Pancreatic head tumors are most commonly responsible for the presentation of obstructive jaundice (63.64\%), followed by jaundice secondary to choledocholithiasis (9.06\%), and stones in vesicular system $(6.06 \%)$. The surgical intervention of choice was a palliative choledochoduodenostomy to divert flow of biliary juices.
\end{abstract}

Keywords: Obstructive Jaundice, Epidemiology, Diagnostic, Treatment, Conakry, Donka

\section{Introduction}

Obstructive jaundice is the consequence of bile stasis resulting from obstruction of bile flow by stones, tumors or inflammation [1]. The most common etiologies of obstructive jaundice are Cholelithiasis and pancreatic cancer, identified in $40 \%$ of total cases. Jaundice is visible on examination, and recognized by the yellow coloration of the skin, cornea and mucous membranes when serum bilirubin levels rise above than 2.5 to $3 \mathrm{mg}$ per dL ( 42.8 to $51.3 \mu \mathrm{mol}$ per L. Icterus is the most common manifestation of a mechanical obstruction in the biliary tract. Other accompanying signs include white stools, dark colored urine, abdominal pain and skin pruritus. It is a serious medical complication as bile reflux can be toxic, cause coagulation defects, renal insufficiency and decrease sensitivity of the humoral or cellular response of the immune system. [2] This most often presents acutely with obstruction secondary to tumor growths). Biochemical liver function tests show elevations in the direct bilirubin, alkaline phosphatase (ALP), and $\gamma$-glutamyltransferase (GGT) values and aspartate transferase (AST) and to a lesser degree, alanine transferase (ALT) values. Common noninvasive imaging studies include trans abdominal ultrasound scan (US), computed tomographic (CT) scan, and magnetic resonance cholangiopancreatography (MRCP). Endoscopic ultrasound (EUS) and endoscopic retrograde cholangiopancreatography (ERCP) are important for both diagnostic and therapeutic 
reasons. [1] Despite the difference in recognition of the nature of obstructive jaundice in different medical centers, finding the causative factor responsible the obstruction is an obligatory preoperative process, as wrongly chosen surgical procedures may have deleterious outcomes [4]

The etiological diagnosis remainsto be an enduringproblem in the departmental context, as reflected by the lack of morphological and biological tests for conducting clinical investigations. [4] This situation is coupled with the scarcity of most advanced and recent treatment resources which are otherwise already in use in developed countries. This particular context has been the most compelling reason for us to write this article with the goal was of reporting our experience while comparing with similar medical literature, in the surgical service in the department of visceral surgery at the National hospital of Conakry in Guinea.

\section{Methodology}

\subsection{Patient and Demographic Data}

Data were collected retrospectively from $1^{\text {st }}$ January 2008 to 31 December 2012 . The study included 23 patients total comprising of 17 male and 16 female subjects with a sex ratio of 1.06:1. The data collected from the patients included age, sex, clinical signs and symptoms, length of hospital stay, echography results; computer tomographic imaging, preoperative diagnosis, treatment modalities and their results. Those with no echography results, and with inoperable disease were excluded from the study.

\subsection{Diagnosis Standard}

On admission, all patients underwent complete standard blood test examinations, including serum bilirubin levels. Patients were considered eligible for the study when they presented obstructive jaundice confirmed by instrumental tests and increased bilirubin serum levels (total bilirubin $>2.0$ $\mathrm{mg} / \mathrm{dL}$ ). Biochemical tests such as Serum levels of CA19-9 and CEA were also measured on admission. Computer tomography imaging and endoscopic ultrasound were performed for all patients to further investigate the etiology of the obstructive jaundice [5]

\subsection{Etiology}

The main etiologic findings in our study related to the obstructive jaundice were periampullary (including pancreatic) malignancy, cholangiocarcinoma, cholelithiasis and others.

\subsection{Management}

\subsubsection{Indication for Surgery}

In our study the main indication for surgery was to relieve the itching, the pruritus and to improve the quality of life of patient.

\subsubsection{Contraindication for Surgery}

The main contraindication for the surgery was that of tumor infiltration into the portal vein, the hepatic vein and the celiac trunk.

\section{Results}

Out of a total of 4127 operations, 33 were performed for treating obstructive jaundice $(0.8 \%)$. The subjects studied included 17 male and 16 female patients at a sex ratio of 1.06 , with age ranging from 5 to 56 years.

The major clinical signs were icterus in all patients, change in general physical appearance was noticeable with anorexia in 30 cases $(90 \%)$, weight loss in 29 cases $(87 \%)$, weakness and fatigue in 24 cases $(72 \%)$. The gallbladder was palpable in 10 cases $(30 \%)$ and anal swelling noted in 1 patient $(3.03 \%)$.

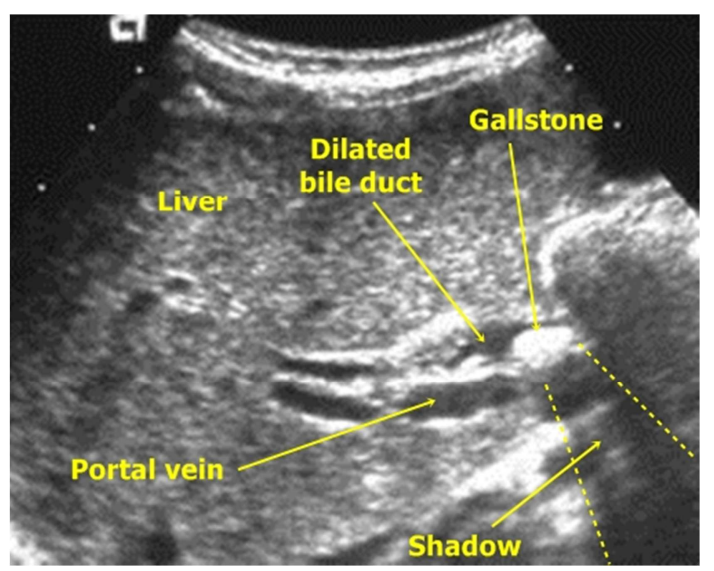

Figure 1. Abdominal ultrasound in a patient presenting with obstructive jaundice, revealing a dilatation of the common bile duct.

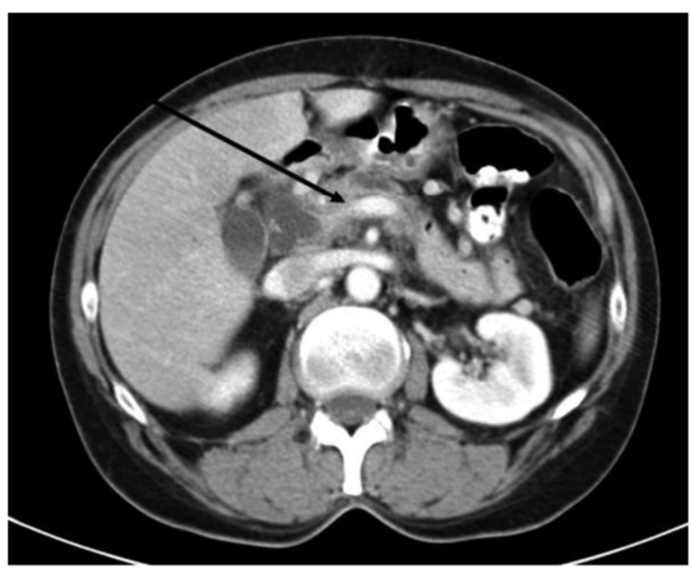

Figure 2. CT scan image shows a pancreatic head carcinoma infiltrating the portal vein, with a dilatation of the biliary tract in a patient who presented with obstructive jaundice.

The delay in admission from beginning of disease manifestation to the time of first consultation was 4 months in 26 cases $(78 \%)$, between 9 and 14 months in 6 cases $(12 \%)$ and 2 years in 1 case $(3.03 \%)$. The ultrasound results which showed dilatation of the extra hepatic biliary ducts in 29 patients $(88 \%)$, also revealed the nature of the obstruction in 15 cases $(55 \%)$

Surgical exploration was performed in order to precisely determine the underlying etiology of the icterus. 
Table 1. List of cases according to etiology.

\begin{tabular}{lll}
\hline Etiology & Number of cases & Percentage (\%) \\
\hline Tumor in head of pancreas & 23 & 69.69 \\
Cholangiocarcinoma & 3 & 9.09 \\
Choledocholithiasis & 3 & 9.09 \\
Gallbladder stones & 2 & 6.06 \\
Ampulla of Vater & 1 & 3.03 \\
Nodular cirrhosis & 1 & 3.03 \\
Total & 33 & 100 \\
\hline
\end{tabular}

The 33 patients of our study were prepared preoperatively with placing of venous access, nasogastric tube, urine catheter and antibiotic administration. In 4 patients, the tumor progression was considered to be too invasive with evidence of metastatic disease and considered unfit for the study. The primary tumor had originated from either the hepatic, main biliary duct, pancreas or hepatic hilum tissues. A medial approach with line of incision below the plane of the umbilicus was chosen for laparotomy.

Table 2. Frequency of surgical procedures performed.

\begin{tabular}{ll}
\hline Techniques & Effective \\
\hline LCD* & 12 \\
Cholecystectomy & 8 \\
LCJ** & 1 \\
ESJ*** & 1 \\
\hline
\end{tabular}

Table 3. Distribution of cases according to surgical procedures performed.

\begin{tabular}{ll}
\hline Techniques & Effective \\
\hline LCD & 12 \\
LCD+choledochotomy & 9 \\
LCD+choledochotomy+ & 4 \\
Cholecystectomy & \\
LCD+cholecystectomy & 1 \\
Cholecystectomy & 2 \\
LCJ****+ESJ+cholecystectomy & 1 \\
\hline
\end{tabular}

The average duration of the hospital stay was 19.57 days with a range of 2 to 104 days.

The postoperative period was uneventful in 22 patients $(67 \%)$, complicated by septicemia and/or cholangitis in 5 cases, hemorrhage in 2 cases, hypovolemic shock in 1 case, and postoperative deaths noted in 10 patients(30\%). Disappearance of the jaundice and pruritus had been noted in 23 patients.

\section{Discussion}

In our institute, the incidence of obstructive jaundice was $0.8 \%$. The results are conforming to other results which we have found in medical literature. Subsequently, authors in Burkina Faso [6] and in Cameroon [7] have respectively reported 2 cases of obstructive jaundice over a period of 6years and 30 cases over 10 years. During 7 years, others have assembled 38 cases of tumor of head of pancreas associated with jaundice presentation. [8] In France, 119 cases of mechanical obstruction with icterus had been collected over a period of 4 years from 1197 to 2001. [11]

The relative rare incidence of this condition is due to a statistical inaccuracy explained by the preference for traditional treatment methods and a number of patients who remain untreated due to lack of financial adequacy. The most commonly affected age group was between 55 and 56 years seen in 12 cases (36\%). Faik M et al [10] in Morocco in 1998 ek Nko'o Amvene S. et al [5] in Cameroon in 1990 have respectively reportedly an average age of 50 years and 48 years. The results of our study have been found to be similar to Takongmo S. et al [9] who in 2010 reported an average age of 55 years compared to 44years in Togo and Chalya P. L. However, the age estimated in France in 2004 was higher, between 64 and 69 years [12] with age extremes of 22 and 102. Young age at presentation is a non-specific finding and may be seen in many other pathologies in Africa. [14]

Male predominance has been noted at 52\% compared to $48 \%$ in females, with a sex ratio of 1.06 . This value is comparable with studies from Cameroon [6] which recorded at $60 \%$ male predominance versus 405 in females at a sex ratio of 1.5 . Our results were lower than other studies which reported $73 \%$ for males against $27 \%$ for females at a sex ratio of 2.66. [4] In their study about surgical jaundice, Traore S. S et al [8] had reported a male-to-femalesex ratio of 3:1.

Skin pruritus and abdominal pain were among the first compelling signs in $78 \%$ and $69 \%$ of patients to seek medical consult. The abdominal pain was located in the right hypochondriac region in $33 \%$ of patients. Studies in Togo similarly reported right hypochondriac pain in $34 \%$ and pruritus in $89 \%$ of patients [3], in Tanzania pruritus was recorded in $77 \%$ and $58 \%$ for abdominal pain [10]. In patients with tumors located in the head of the pancreas, $69 \%$ reported to have abdominal pain.

The majority of patients had experienced weight loss (90\%) and fatigue (87\%). In addition, there was a change in general appearance in 21 cases $(63 \%)$. Our results were consistent with those of Berrada S. et al [13] who reported a change in general appearance in $87 \%$ but higher than N'ko'o Amvene S. et al [5] (63.63\%), Chalya P. L et al. (61\%) [12] and Sonhaye et al. (77\%) [4].

Jaundice was reported in $100 \%$ of cases and scratch marks in $42 \%$. Other manifestations observed were hepatomegaly (72\%), enlarged gallbladder (30\%). Our results were superior to those of Faik M. et al [10] who recorded hepatomegaly in $23 \%$ and enlarged gallbladder in $34 \%$ during physical examination.

The ultrasound results were appreciated in $100 \%$ in several studies $[4,13,8,3]$. However, the biological tests did not show satisfying specificity. The association of the level of serum level of tumor markers such as fetal antigen, CA19-9 has $100 \%$ sensitivity in diagnosis of pancreatic cancer. [8] In this service, however, these tests are not performed. Abdominal ultrasound is the diagnostic test of choice test when jaundice is present. [2] It has high sensitivity for detection of dilatation of bile ducts and obstruction [14]. Biliary tract dilatationseen in 29 patients $(87 \%)$ assisted in revealing the exact etiology of the jaundice in 15 patients $(45 \%)$. Studies showed that $93 \%$ of diagnoses were made 
with ultrasound at a sensitivity of $100 \%$ and specificity of $80 \%$. [3, 7] However, ultrasound is less efficient in determining the nature of the stenosis if the obstruction is not caused by a tumor [14]. Not all cases of obstructive jaundice can be diagnosed based solely on ultrasound results thus driving surgeons to opt for exploratory laparotomy. [7]. Despite the advent of advanced and more complex imaging techniques, the hospitals in this developing section of the world are unable to afford the cost of supplying expensive equipment [2]. Ultrasound imaging results are variable depending on the experience and skill of the physician performing the technique. [15] The definite etiology of the condition is rarely determined by clinical and imaging tests alone and therefore, laparotomy is the only alternative to finding the cause. [7]

The principal etiologies of jaundice discovered during surgery were tumor in head of pancreas in 23 cases $(63 \%)$, cholethiasis $9 \%$. Our results were superior to Takongmo S. et al [9] who reported $53.3 \%$ and $6.6 \%$ for tumors of the pancreas and cholelithiasis respectively, and Sonhaye et al. [4] with $46.03 \%$ and $19.05 \%$ respectively, but inferior to Chalya P. L. et al. [12] who had $64.7 \%$ for tumors in pancreatic head and $62.5 \%$ for cholelithiasis.

Principal palliative management comprised of a diversion of the biliary duct in 30 cases $(90.9 \%)$, with laterolateral choledoduodenostomy in majority of patients $(87 \%)$. A choledotomy was performed in 14 cases $(42 \%)$ for stone extraction and was followed by a choledochoduodenostomy in 11 cases $(33 \%)$.

Takongmo S. et al [9] similarly performed diversion of biliary tract $(90 \%)$, but with $56.6 \%$ of choledochoduodenostomies, $26.6 \%$ of cholecystectomy et $6.6 \%$ of choledochotomy. Alincourt A. et al [13] placed biliary prosthesis in all of their patients while Vidal V. et al [11] did a percutaneous drainage.

The choice for performing choledochoduodenostomy is related to its relative simplicity and rapidity of completion of the procedure, thus, being appropriate for patients in poor health. [15]

Curative surgery for tumors of the head of the pancreas $(5 \%)$ is rarely considered as first choice. In cases of malignant obstruction, if an early diagnosis is made then curative resection may be possible, otherwise only palliative procedures are performed; in inoperable malignant cases endoprosthesis may be used to relieve the obstruction. [8, 16]. Choledochoduodenostomy or hepatojejunostomy are both related to a significantly higher mortality rate [16]. The use of biliary prosthesis is preferred over surgery to prevent unnecessary laparotomies $[11,13,8]$. However, the result is short-lived as regular stent replacement is required [15]. While endoscopic intervention is not yet available in the local hospitals, laparotomy gives way to ample visualization of the tumor and assists to decide on its resectability [13, 8].

The procedures of choice in 3 cases $(9.09 \%)$ of biliary stones were cholecystectomy, choledocoduodenostomy and choledocotomy. The management of the biliary stones is based on the competence of the surgeon and clinical presentation. The choice for the procedure can be either ERCP with sphincterotomy and extraction of stones or a complete surgical approach with cholecystectomy and cholangiography with laparoscopic exploration of biliary tracts. [19]. The technique of biliary diversion prevents the recurrence of obstruction by stones [20].

The signs have regressed in 23 patients (69\%) but persisted in 7 patients $(21 \%)$, with 10 cases of death reported $(30 \%)$. However, 1 post-surgical patient had deteriorating health condition despite disappearance of jaundice. Berrada S. et al [15] had reported complete disappearance of jaundice and pruritus in $98 \%$ and mortality rate of $8,7 \%$ compared to Tankongmo S. et al [9] with a lower mortality rate of $6,6 \%$. The high mortality rates are accounted for by the presentation of the disease in its late course. [21]. Postoperative mortality rates are lower in patients had received prosthesis, which is possible to perform in $70-95 \%$ of cases, either via endoscopic or laparoscopic route or percutaneous route with radiological assistance, and associated with a combined mortality rate of $3 \%$ only [12].

\section{Conclusion}

Mechanical obstructive jaundice is a rare pathology in the service. It has a male predominance and arises mostly around the age of 50. Ultrasound sonography represents an important paraclinical diagnostic test to visualize the obstruction along the biliary tract.

In cases where malignancies are the causes, presence of icterus signifies an advanced tumor progression stage. Due to the lack of endoscopic diagnostic and treatment techniques, definite diagnosis can only be made in perioperative phase. The management chiefly consists of surgical intervention through a palliative deviation of biliary tract. Therefore, improvement of the prognosis and chance of recovery depend on the necessity of making an early diagnosis and rapid intervention for jaundice.

\section{Abbreviations}

$\mathrm{LCD}=$ laterolateral choledochoduodenostomy (side-to-side choledochoduodenostomy)

$\mathrm{LCJ}=$ laterolateral choledochojejunostomy (side-to-side choldochojejunostomy)

$\mathrm{ESJ}=$ end to side jejunojejunostomy (end-to-side jejunostomy)

$\mathrm{LC}=$ laterolateral choledochojejunostomy (side-to-side choledochojejunostomy)

\section{References}

[1] Reem Zeyad Sharaiha MD, MScand Zhiping Li MDObstructive Jaundice Current Surgical Therapy, 427-429 Copyright (C) 2014

[2] Fattorusso V.; Ritter O.: VADEMECUM CLINIQUE: du diagnostic au traitement Masson; 1988; $12^{\text {ème }}$ édition: 976-978 
[3] Valls C.: L'ictère nu: rôle du radiologue dans la prise en charge diagnostic et thérapeutique Journal de la radiologie; Avril 2006; vol 87; N4-C2: 460-478

[4] Sonhaye L. et al: L'échographie dans la cholestase extrahépatique chez l'adulte à Lomé JOURNAL AFRICAIN D'IMAGERIE MEDICAL; 2012; VOL3; N9 http://jaimonline.net/index.php/jaim/article/view/120/pdf_61 consulté le $1^{\text {er }}$ février 2015

[5] N'ko'oAmvene S.; Juimo A. G.; Malonga E. E: Ictères obstructifs à Yaoundé: exploration radiologique Médecine d'Afrique Noire; 1990; 37(12): 783-786

[6] Daniele Marrelli M. D., Stefano Caruso M. D., Corrado Pedrazzani M. D., Alessandro Neri M. D., Eduardo Fernandes M. D., M. R. C. S., Mario Marini M. D., Enrico Pinto M.D.and Franco Roviello M. D. CA19-9 serum levels in obstructive jaundice: clinical value in benign and malignant conditionsAmerican Journal of Surgery, The, 2009-09-01, Volume 198, Issue 3, Pages 333-339, Copyright (C) 2009 Elsevier Inc.

[7] Vienne A.; Obertin O.; Chaussade S.; Dousset B.; Prat F.: Ictères néoplasiques: Pour ou contre le drainage biliaire préopératoire ? Cancero dig.; 2010; Vol2 ํ3: 214-223

[8] Traoré S. S.; Ouédraogo D.; Ilboudo P. D.; Kafando R.; Dakouré R.; Sanou A. Les ictères chirurgicaux au Centre Hospitalier National Yalgado Ouédraogo (CHNYO) Ouagadougou (BF). Burkina Médical; 1997; vol 1: 19-22

[9] Takongmo S.; Guifo M. L.; PisohTangnyin C.; Talla P.; Monabang C.; Essame-Oyono J. L.; Sosso M. A. Prise en charge des ictères obstructifs à Yaoundé. Analyse d'une série de trente cas. Health sci. Dis; 2010; vol 11; (20) http://www.hsd-

fmsb.org/index.php/hsd/article/view/50/pdf_90. consulté le 11 février 2014

[10] Faik M. et coll.: Cancer de la tête du pancréas au stade d'ictère (à propos de 38 cas) Médecine du Maghreb 1998; N72: 6-8

[11] Vidal V.; Ho C. S.; Petit P.: Complications infectieuses précoces au cours des drainages biliaires percutanés transhépatiques, J. radiol 2004; Edition Française de radiologie; 85: 1707-9
[12] Chalya P. L.; Kanumba E. S.; MabulaMchembe Etiological spectrum and treatment outcome of Obstructive jaundice at a University teaching Hospital in northwestern Tanzania: A diagnostic and therapeutic challenges BMC Research Notes 2011, 4: 147

[13] Alincourt A.; Hamy A.; Thibaud C.; Redon H.; Paineau J.; Lerat F.: Ictères obstructifs néoplasiques: apport des prothèses métalliques percutanées GastroenterolClinBiol 2000; 24: 770775

[14] Koffi E.; Yenon K.; Ehua S.; Coulibaly A.; Kouassi J. C.; Kanga M.: La lithiase de la voie biliaire principale en milieu ivoirien. Médecine d'Afrique Noire; 1999; 46 (2): 114-118

[15] Berrada S.; D'Klissy M.; Ridai M.; Zerouali N. O Place de la déviation bilio-digestive dans le traitement du cancer de la tête du pancréas. Médecine du Maghreb 1992; N³6: 21-23

[16] Napoléon B.: Apport des nouvelles techniques endoscopiques dans l'exploration des sténoses de la VBP Post'U; 2012: 95100

[17] Takongmo S.; Nko'Amveme S.; Biwole M.; Essame J. L.; Masso-Misse P.; Malonga E. Une démarche diagnostic des cancers du pancréas exocrine en milieu tropical Médecine d'Afrique Noire; 1994; 41 (1): 56-59

[18] Sauvanet A.: Sténoses biliaires ou duodénales: chirurgie ou endoscopie. Les journées EPU Paris VII- journée de gastroentérologie; janvier 2006: 52-57

[19] Yenon K.; Benchelial Z.; Huten N.: Résultats du traitement laparoscopique de la lithiase du cholédoque: notre expérience à propos d'une série de 62 cas Rev. Int. Sc. Med.; 2006; vol 8 $\mathrm{N}^{\circ} 1: 18-22$

[20] Breda Y.; Heng T. K.; Faucompret S.; Louis C.; Deligny M.: Intérêt de la déviation bilio-digestive dans la pathologie biliaire extrême-orientale: étude rétrospective sur 5 ans à l'hôpital CALMETTE DE PHONOM PENH (Royaume du Cambodge) Médecine Tropicale; 2000; 60.4: 114-118

[21] Trigui B. et coll.: Facteurs pronostiques des cancers avancés du pancreas. Analyse multifactorielle et score prédictif de survie Ann Chir 2000; 125: 625-30, Copyright (C) 2014 